\title{
KENYAMANAN TERMAL GEDUNG SETDA KUDUS
}

\author{
Farid Firman Syah, Muhammad Siam Priyono Nugroho \\ Program Studi Teknik Arsitektur, Fakultas Teknik, Universitas Muhammadiyah Surakarta \\ Jl. A. Yani Tromol Pos 1 Pabelan Kartasura Sukoharjo 57102 Telp 0271-717417 \\ E-mail: siam.priyono@ums.ac.id
}

\begin{abstract}
ABSTRAK
Indonesia memiliki iklim tropis yang lembab sehingga suhu dan kelembaban udaranya sangat tinggi. Kondisi udara tersebut dapat berpengaruh terhadap produktifitas kerja. Jalan pintas yang sering ditempuh adalah penggunaan pendingin udara. Pengkondisian udara secara alami semestinya diupayakan untuk ditempuh agar biaya operasional bangunan dapat ditekan. Penelitian mengenai kenyamanan termal ini dilakukan di suatu komplek gedung pemerintahan dengan studi kasus di Gedung Setda Kudus untuk mengetahui kondisi termal di ruang kerja. Metode yang dilakukan adalah pengukuran lapangan dan analisis berdasarkan teori kenyamanan. Hasil yang diperoleh menunjukkan bahwa kondisi termal di dalam bangunan tidak memenuhi syarat dan harus dilakukan upaya-upaya perbaikan.
\end{abstract}

\section{Kata Kunci: kenyamanan, kudus, setda, termal, ventilasi}

\section{PENDAHULUAN}

Secara geografis Indonesia berada dalam garis katulistiwa atau tropis, namun secara termis (suhu) tidak semua wilayah Indonesia merupakan daerah tropis. Daerah tropis menurut pengukuran suhu adalah daerah tropis dengan suhu rata-rata $20^{\circ} \mathrm{C}$, sedangkan rata-rata suhu di wilayah Indonesia umumnya dapat mencapai $35^{\circ} \mathrm{C}$ dengan tingkat kelembaban yang tinggi, dapat mencapai $85 \%$ (iklim tropis panas lembab). Keadaan ini terjadi antara lain akibat posisi Indonesia yang berada pada pertemuan dua iklim ekstrim (akibat posisi antara 2 benua dan 2 samudera), dan perbandingan luas daratan dan lautannya. Kondisi ini kurang menguntungkan bagi manusia dalam melakukan aktifitasnya sebab produktifitas kerja manusia cenderung menurun atau rendah pada kondisi udara yang tidak nyaman seperti halnya terlalu dingin atau terlalu panas. Produktifitas kerja manusia meningkat pada kondisi suhu (termis) yang nyaman (Idealistina, 1991).
Suhu nyaman termal untuk orang Indonesia berada pada rentang suhu $22,8^{\circ} \mathrm{C}-25,8^{\circ} \mathrm{C}$ dengan kelembaban $70 \%$. Langkah yang paling mudah untuk mengakomodasi Kenyamanan tersebut adalah dengan melakukan pengkondisian secara mekanis (penggunaan AC) di dalam bangunan yang berdampak pada bertambahnya penggunaan energi listrik. Cara yang paling murah memperoleh kenyamanan termal adalah secara alamiah melalui pendekatan arsitektur, yaitu merancang bangunan dengan mempertimbangkan orientasi terhadap matahari dan arah angin, pemanfaatan elemen arsitektur dan material bangunan, serta pemanfaatan elemen-elemen lansekap.

Dalam proses perancangan arsitektur dengan memakai pendekatan iklim, terdapat empat variabel yang dominan, yaitu 1). suhu udara ( $\mathrm{T}$, ${ }^{\circ}$ Celcius), 2). kelembaban relatif $(\mathrm{RH}), 3)$. radiasi matahari (GT, $\left.\left.{ }^{\circ} \mathrm{Celcius}\right), 4\right)$. kecepatan angin yang ada $(\mathrm{V}, \mathrm{m} / \mathrm{dt})$ 
Tabel 1. Suhu Nyaman menurut Standar Tata Cara Perencanaan Teknis Konservasi Energi pada Bangunan Gedung

\begin{tabular}{|l|c|c|}
\hline & Temperature Efeektif (TE) & Kelembaban (RH) \\
\hline - Sejuk nyaman & $20,5^{\circ} \mathrm{C}-22,8^{\circ} \mathrm{C}$ & $50 \%$ \\
\hline Ambang atas & $24^{\circ} \mathrm{C}$ & $80 \%$ \\
\hline - Nyaman optimal & $22,8^{\circ} \mathrm{C}-25,8^{\circ} \mathrm{C}$ & $70 \%$ \\
\hline Ambang atas & $28^{\circ} \mathrm{C}$ & $60 \%$ \\
\hline - Hangat nyaman & $25,8^{\circ} \mathrm{C}-27,1^{\circ} \mathrm{C}$ & \\
\hline Ambang atas & $31^{\circ} \mathrm{C}$ & \\
\hline
\end{tabular}

Sumber : Soegiyanto, 1990)

Sekretariat Daerah (Setda) merupakan suatu unsur pembantu pimpinan pemerintah daerah yang dipimpin oleh Sekretaris Daerah. Sekretaris Daerah bertugas membantu kinerja kepala daerah yaitu Bupati. Gedung Sekretariat Daerah Kabupaten Kudus adalah gedung yang menampung segala aktivitas Sekretariat Daerah , dan merupakan sarana \& prasarana perkantoran lingkungan Sekretariat Daerah Kabupaten Kudus. Gedung Sekretariat Daerah Kabupaten Kudus berada dalam kawasan Kantor Kabupaten Kudus, letaknya yaitu sebelah Barat Pendopo Kabupaten. Gedung sekretariat daerah yang ada pada saat ini dirasa kurang memenuhi serta terasa tidak nyaman, dikarenakan bangunan yang ada pada saat ini merupakan bangunan lama yang hanya mendapatkan renovasi/rehab ringan. Bukaan atau ventilasi yang adapun kurang optimal, yang mengakibatkan tubuh terasa gerah pada saat AC padam karena pemadaman listrik ataupun adanya kerusakan AC. Hal ini yang menyebabkan di dalam ruang kantor sekretariat daerah terasa kurang nyaman yang tentunya akan berpengaruh pada kinerja pejabat sekretariat daerah dan staf-stafnya.

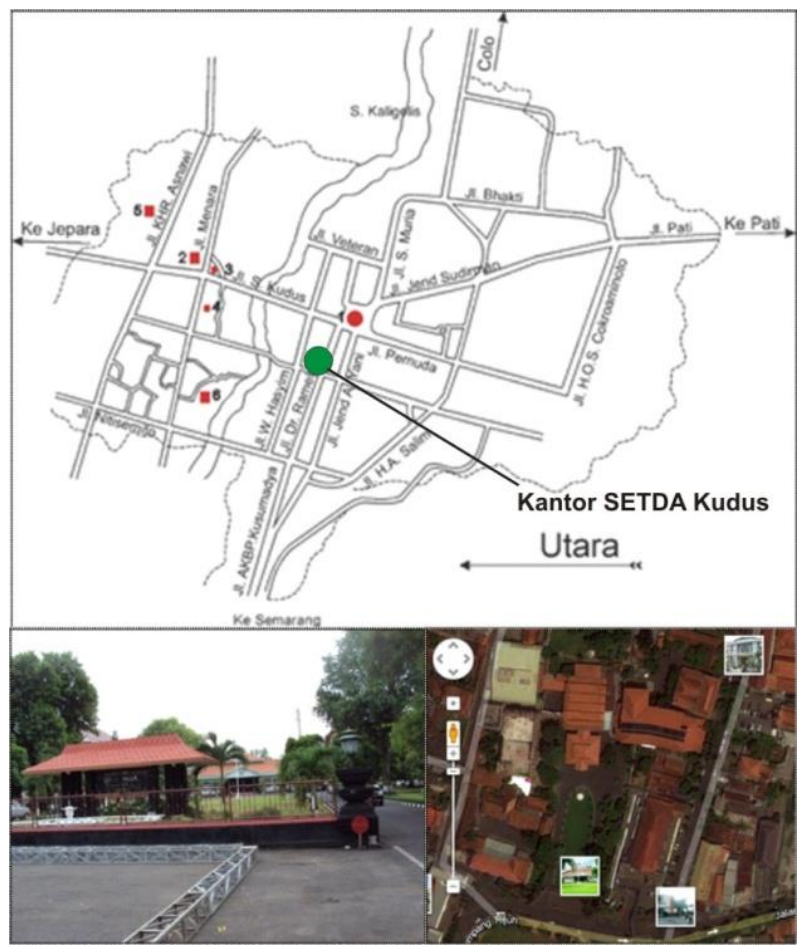

Gambar 1. Peta Lokasi Kantor Kabupaten Kudus (Sumber: http://www.kudus.go.id/dan ilustrasi penulis, 2012) 


\section{METODE PENELITIAN}

Lokasi penelitian berada di Kudus tepatnya Kompleks Gedung Perkantoran Sekretariat Daerah Kabupaten Kudus, seperti terlihat pada Gambar 2.

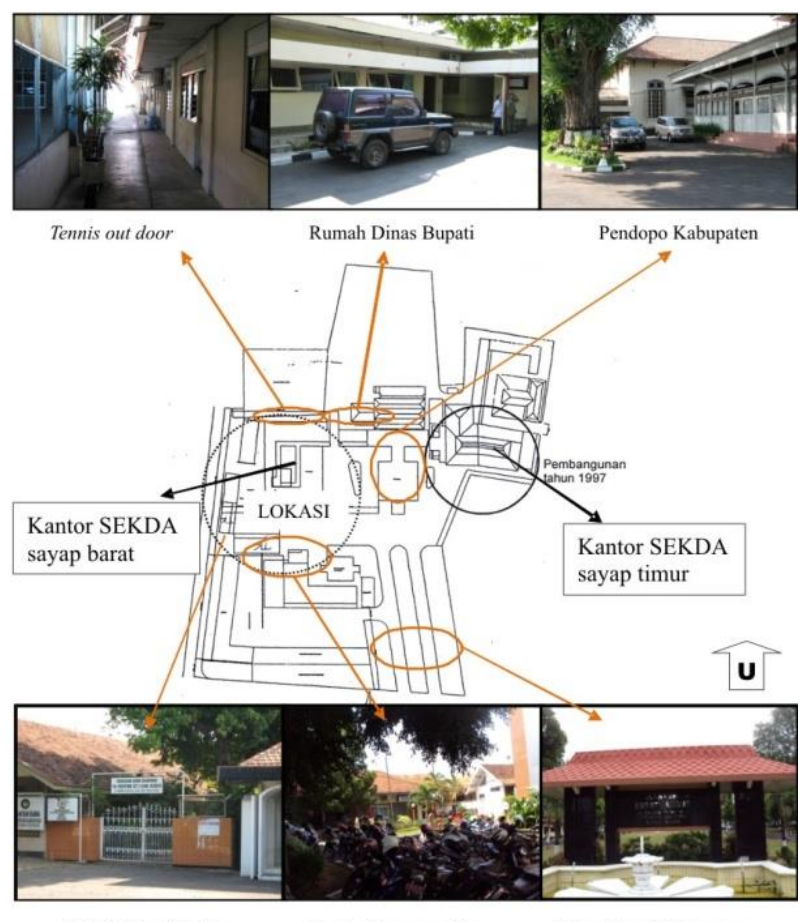

TK \& Jalan Masjid Kantor Darmawanita Jalan Masuk Kabupaten

Gambar 2. Lokasi Penelitian

(Sumber: Analisa Peneliti, 2011)

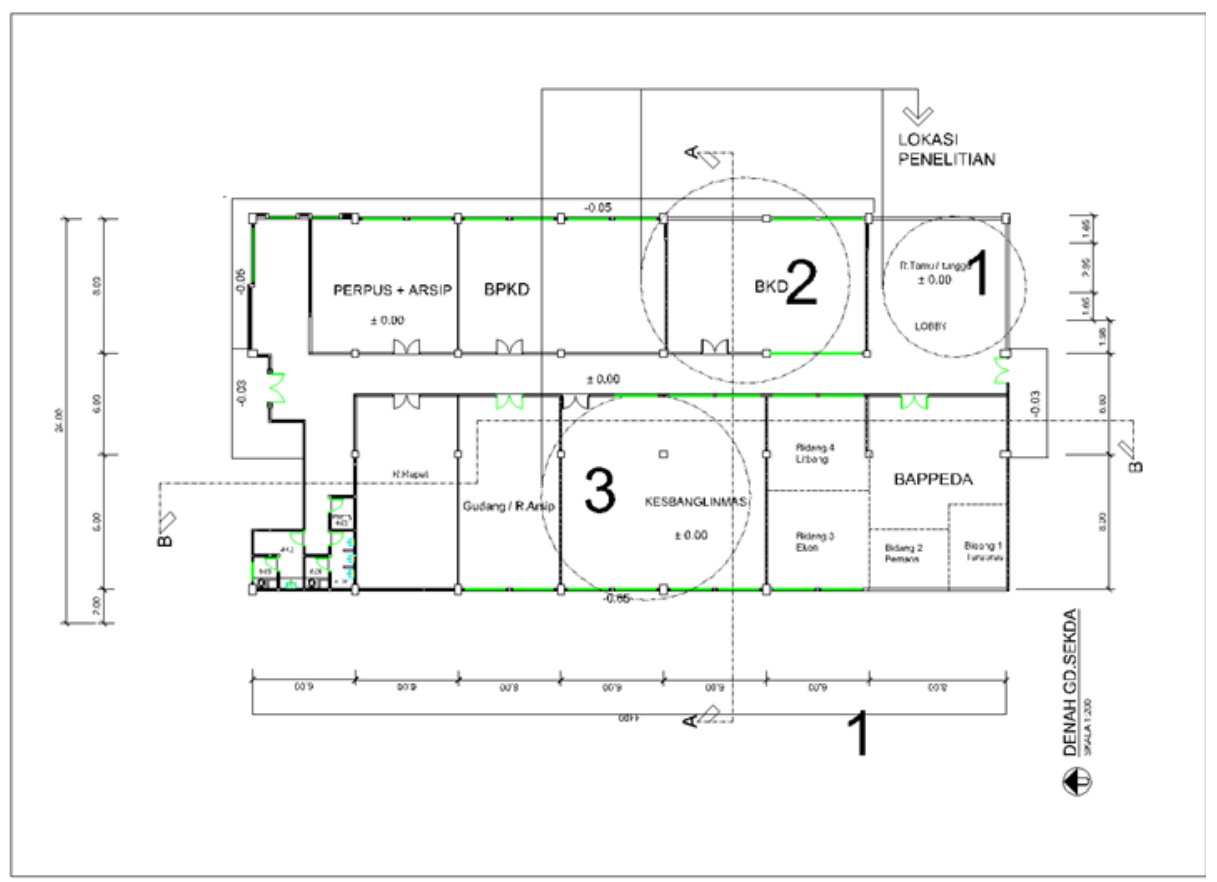

Gambar 3. Denah gedung SEKDA

(Sumber: Data Kab. Kudus, 2011) 
Ruangan yang akan diteliti diambil sampel sebanyak 3 ruang yaitu 1).R. tamu dan Lobby.2). R. Badan Kepegawaian Daerah (BKD). 3),R. Kantor Kesatuan Bangsa dan Perlindungan Masyarakat (KESBANGLINMAS).

Dalam penelitian ini digunakan metode Penelitian Induktif, yaitu yang dibuat untuk membangun teori berdasarkan data-data lapangan. Cara pengumpulan data dilakukan dua tahap, yaitu pengumpulan data primer dan data sekunder. Data primer adalah data yang di ambil langsung di lapangan. Data sekunder data yang diperoleh dari instansi terkait. Data primer yang diambil dilapangan meliputi; mengukur suhu udara ( $\left.\mathrm{T},{ }^{\circ} \mathrm{Celcius}\right)$, mengukur kelembaban relatif $(\mathrm{RH})$, mengukur radiasi matahari (GT, ${ }^{\circ}$ Celcius), mengukur kecepatan angin yang ada (V, m/dt). Psychrometric Chart dan Nomogram Temperatur Efektif juga digunakan dalam pengukuran ini. Sedangkan data sekunder yang dikumpulkan meliputi layout bangunan di kawasan kantor Kabupaten, sampel ruang yang diteliti serta denah lokasi. Untuk mengetahui tingkat kenyamanan awal dalam gedung, peneliti melakukan wawancara dengan beberapa karyawan (5-7 orang tentang kenyamanan dalam Gedung Sekretariat Daerah.

\section{HASIL PENELITIAN \\ Hasil Pengujian Pada R. Tamu - Lobby}

Survei dilakukan pada jam kerja khususnya dimana kondisi udara dirasa ideal untuk menentukan kenyamanan suatu tempat yaitu pada jam 13.00 WIB dimana cuaca terasa panas, dari hasil survei didapatkan data sebagai berikut:

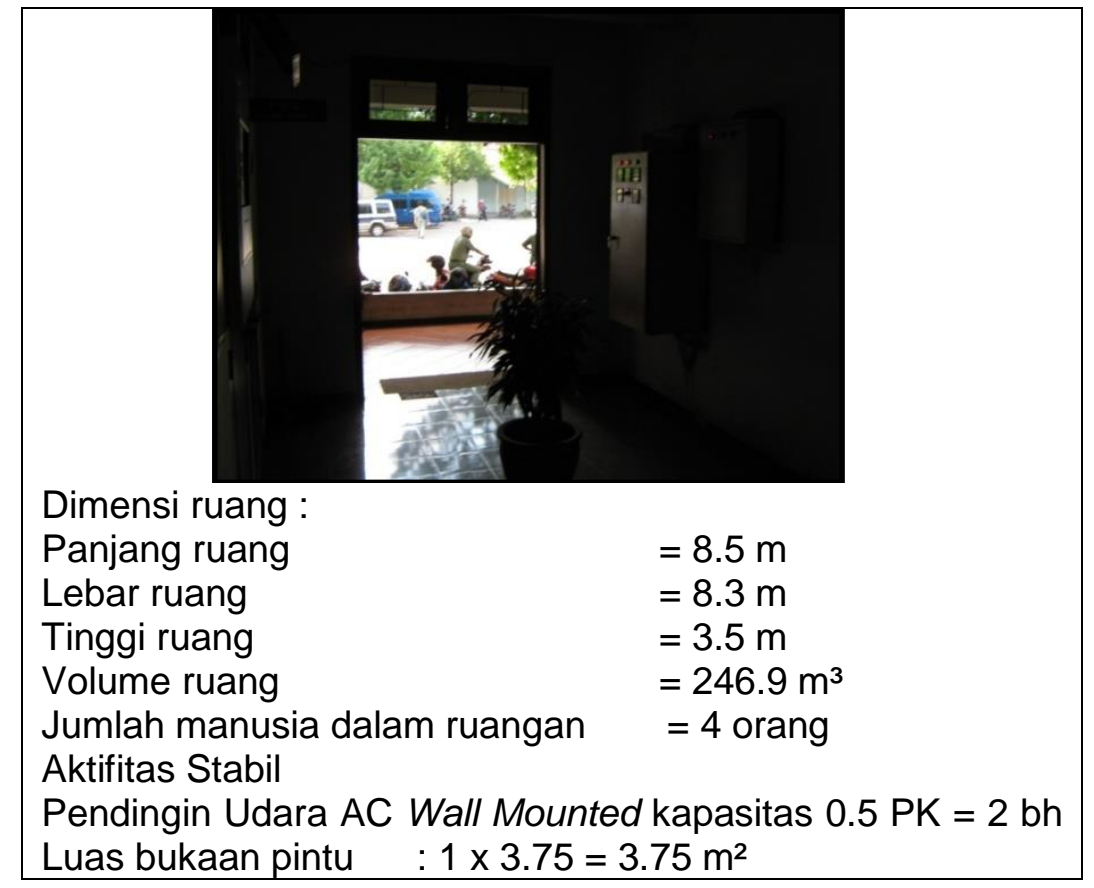

Gambar 4. Pintu R. Tamu - Lobby (Sumber : Survey lapangan, 2011)

Dari hasil survey, Ruang Tamu - Lobby termasuk dalam kategori kondisi lingkungan yang tidak nyaman dengan suhu efektif $34.5^{\circ} \mathrm{C}$, karena kondisi lingkungan yang sukar mulai dirasakan adalah pada suhu $33.5^{\circ} \mathrm{C}-$ 35.5드 (Idealistina, 1991).

\section{Hasil Pengujian R. Badan Kepegawaian Daerah ( BKD )}

Survei dilakukan pada jam kerja khususnya dimana kondisi udara dirasa ideal untuk menentukan kenyaman suatu tempat yaitu pada jam 13.00 WIB dimana cuaca terasa panas, dari hasil survey didapatkan data sebagai berikut: 

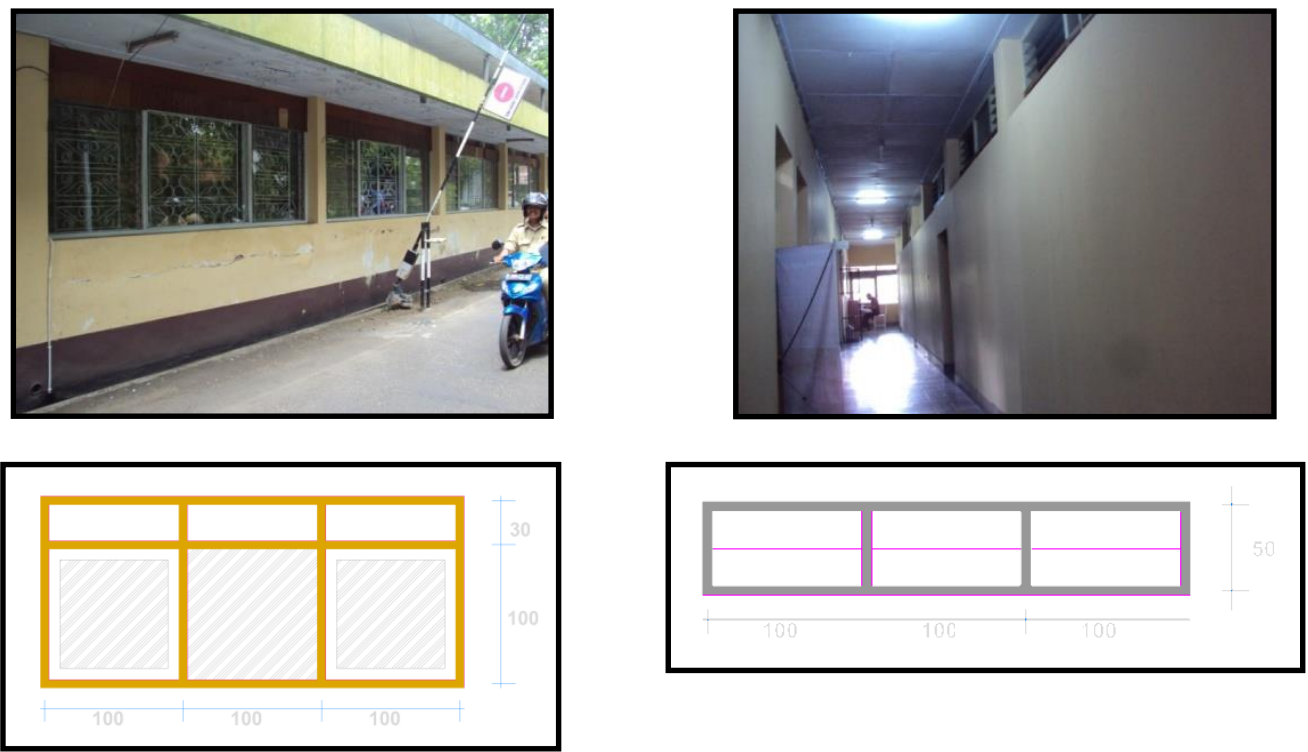

Dimensi ruang :

Panjang ruang

$=12 \mathrm{~m}$

Lebar ruang

$=8 \mathrm{~m}$

Tinggi ruang

$=3.5 \mathrm{~m}$

Volume ruang

$=336 \mathrm{~m}^{3}$

Jumlah manusia dalam ruangan

$=3$ orang

Aktifitas Stabil

Pendingin Udara AC Wall Mounted kapasitas $0.5 \mathrm{PK}=2$ bh

Luas bukaan pintu $: 1 \times 3.75=3.75 \mathrm{~m}^{2}$

Luas bukaan jendela : $2 \times 3.9=7.8 \mathrm{~m}^{2}$

Luas bukaan bouven : $2 \times 1.5=3 \mathrm{~m}^{2}$

Gambar 5. Ruang BKD

(Sumber: Survey lapangan, 2011)

Dari hasil pengukuran, Ruang Badan Kepegawaian Daerah termasuk dalam kategori kondisi lingkungan yang tidak dapat ditolerir dengan suhu efektif $35.5^{\circ} \mathrm{C}$.

\section{Hasil Pengukuran Ruang \\ KESBANGLINMAS}

Survey dilakukan pada jam kerja khususnya dimana kondisi udara dirasa ideal untuk menentukan kenyaman suatu tempat yaitu pada jam 13.00 WIB dimana cuaca terasa panas, dari hasil survey didapatkan data sebagai berikut: 


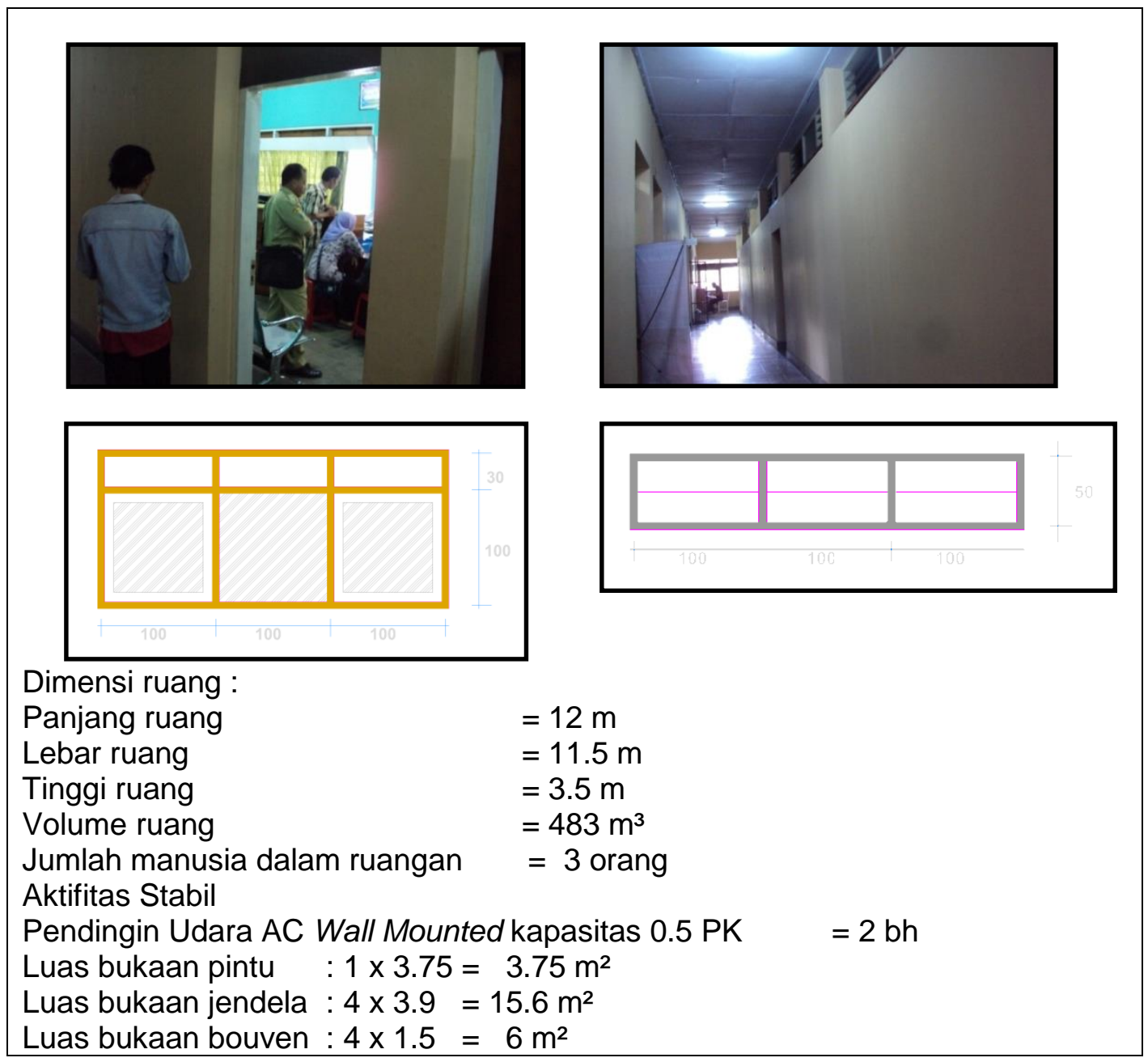

Gambar 6. Ruang KESBANGLINMAS

(Sumber: Survey lapangan, 2011)

Dari hasil survey, Ruang Kantor Kesatuan Bangsa dan Perlindungan Masyarakat (KESBANGLINMAS) termasuk dalam kategori kondisi lingkungan yang tidak dapat di tolerir dengan suhu efektif $35.5^{\circ} \mathrm{C}$. Data yang diambil untuk diolah adalah pada Tabel 3 dikarenakan data tersebut diambil ketika AC/pendingin udara dimatikan lebih dari 24 jam sehingga tidak terpengaruh kinerja dari penghawaan buatan. Tabel 2 disajikan untuk data pembanding.
Menurut penelitian Lippsmeier, batas-batas kenyamanan manusia untuk daerah khatulistiwa adalah $19^{\circ} \mathrm{C}$ TE (batas bawah) $26^{\circ} \mathrm{C}$ TE (batas atas). Pada temperatur $26^{\circ} \mathrm{C}$ TE umumnya manusia sudah mulai berkeringat. Daya tahan dan kemampuan kerja manusia mulai menurun pada temperatur $26^{\circ} \mathrm{C}$ TE $-30^{\circ} \mathrm{C}$ TE. Mengacu pada penelitian Lippsmeier maka dapat disimpulkan bahwa ruangan pada Gedung Sekretariat Daerah Kabupaten Kudus tidak nyaman. 
Tabel 2. Hasil pengukuran suhu udara, kelembaban dan kecepatan angin

\begin{tabular}{|c|c|c|c|c|c|c|c|c|c|}
\hline \multirow{2}{*}{$\begin{array}{c}\text { Ruang } \\
\text { Amatan }\end{array}$} & \multirow{2}{*}{$\begin{array}{l}\text { Waktu } \\
\text { Amatan }\end{array}$} & \multirow{2}{*}{$\begin{array}{c}\text { Suhu } \\
\text { Ruang } \\
\left({ }^{\circ} \mathrm{C}\right)\end{array}$} & \multirow{2}{*}{$\begin{array}{c}\text { Kecepat } \\
\text { an } \\
\text { Angin } \\
\text { (m/s) }\end{array}$} & \multicolumn{4}{|c|}{$\begin{array}{c}\text { Suhu }\left({ }^{\circ} \mathrm{C}\right) \text { dan Kelembaban } \\
\text { Udara }\left({ }^{\circ} \mathrm{C}\right)\end{array}$} & \multirow{2}{*}{$\begin{array}{c}\text { Suhu Efektif } \\
\text { Rg } \\
\text { Nomogrm }\end{array}$} & \multirow{2}{*}{$\begin{array}{c}\text { Suhu } \\
\text { Luar } \\
\text { Ruang } \\
\left({ }^{\circ} \mathrm{C}\right)\end{array}$} \\
\hline & & & & $\begin{array}{l}\text { Dry } \\
\left({ }^{\circ} \mathrm{C}\right)\end{array}$ & $\begin{array}{l}\text { Kelen } \\
\text { (Psiko }\end{array}$ & $\begin{array}{l}\text { Udara } \\
\text { (Hygro }\end{array}$ & $\begin{array}{l}\text { Wet } \\
\left({ }^{\circ} \mathrm{C}\right)\end{array}$ & & \\
\hline \multirow{2}{*}{$\begin{array}{c}\text { Ruang } \\
\text { Tamu\& } \\
\text { Lobby }\end{array}$} & 10.00 & 23.8 & 0.5 & 25.4 & 62 & 61 & 20.5 & 22.8 & 27 \\
\hline & 13.00 & 24.2 & 0.5 & 24.8 & 62 & 61 & 20 & 19.8 & 28 \\
\hline \multirow{2}{*}{$\begin{array}{c}\text { Ruang } \\
\text { BKD }\end{array}$} & 10.00 & 24.2 & 0.5 & 24.8 & 62 & 61 & 20.2 & 20 & 27 \\
\hline & 13.00 & 24.4 & 0.5 & 24.8 & 66 & 66 & 21.6 & 24.3 & 28 \\
\hline \multirow{2}{*}{$\begin{array}{c}\text { Ruang } \\
\text { KESBA } \\
\text { NGLINM } \\
\text { AS } \\
\end{array}$} & 10.00 & 24.2 & 0.5 & 24.8 & 62 & 61 & 20.2 & 20 & 27 \\
\hline & 13.00 & 24.4 & 0.5 & 24.8 & 66 & 66 & 21.6 & 24.3 & 28 \\
\hline
\end{tabular}

(Sumber: Hasil pengukuran dan analisis peneliti, 26 Oktober 2011)

Keterangan: Pengambilan data setelah AC dimatikan selama 10 menit.

Tabel 3. Hasil pengukuran suhu udara, kelembaban dan kecepatan angin

\begin{tabular}{|c|c|c|c|c|c|c|c|c|c|}
\hline \multirow{2}{*}{$\begin{array}{l}\text { Ruang } \\
\text { Amatan }\end{array}$} & \multirow{2}{*}{$\begin{array}{c}\text { Waktu } \\
\text { Amata } \\
\mathbf{n}\end{array}$} & \multirow{2}{*}{$\begin{array}{c}\text { Suhu } \\
\text { Ruang } \\
\left({ }^{\circ} \mathbf{C}\right)\end{array}$} & \multirow{2}{*}{$\begin{array}{l}\text { Kecepat } \\
\text { an } \\
\text { Angin } \\
(\mathrm{m} / \mathrm{s})\end{array}$} & \multicolumn{4}{|c|}{ Suhu $\left({ }^{\circ} \mathbf{C}\right)$ dan Kelembaban Udara $\left({ }^{\circ} \mathbf{C}\right)$} & \multirow{2}{*}{$\begin{array}{c}\text { Suhu Efektif } \\
\text { Rg } \\
\text { Nomogram }\end{array}$} & \multirow{2}{*}{$\begin{array}{c}\text { Suhu } \\
\text { Luar } \\
\text { Ruang } \\
\left({ }^{\circ} \mathrm{C}\right)\end{array}$} \\
\hline & & & & $\begin{array}{l}\text { Dry } \\
\left({ }^{\circ} \mathrm{C}\right)\end{array}$ & $\begin{array}{r}\text { Keler } \\
\text { (Psiko }\end{array}$ & $\begin{array}{l}\text { Udara } \\
\text { Hygrom }\end{array}$ & Wet $\left({ }^{\circ} \mathrm{C}\right)$ & & \\
\hline \multirow{2}{*}{$\begin{array}{l}\text { Ruang } \\
\text { Tamu\& } \\
\text { Lobby }\end{array}$} & 10.00 & 30 & 0.25 & 28.4 & 65 & 64 & 27.5 & 25 & 27 \\
\hline & 13.00 & 31.5 & 0.25 & 34 & 72 & 68 & 29 & 31.5 & 28 \\
\hline \multirow{2}{*}{$\begin{array}{c}\text { Ruang } \\
\text { BKD }\end{array}$} & 10.00 & 30.4 & 0.25 & 32 & 65 & 64 & 28.5 & 30 & 27 \\
\hline & 13.00 & 34.5 & 0.25 & 36.5 & 74 & 66 & 30.7 & 33 & 28 \\
\hline \multirow{2}{*}{$\begin{array}{c}\text { Ruang } \\
\text { KESBA } \\
\text { NGLINM } \\
\text { AS }\end{array}$} & 10.00 & 31.2 & 0.25 & 34.7 & 64 & 63 & 28.7 & 31 & 27 \\
\hline & 13.00 & 34.5 & 0.25 & 36.5 & 74 & 57 & 29 & 33 & 28 \\
\hline
\end{tabular}

(Sumber: Hasil pengukuran dan analisis peneliti, 6 November 2011)

Keterangan : Pengambilan data setelah AC dimatikan lebih dari 24 jam.

\section{PEMBAHASAN}

\section{Analisa Orientasi Bangunan Gedung Sekretariat Daerah terhadap Matahari}

Bangunan gedung sekretariat daerah mempunyai orientasi terhadap matahari dengan sisi bangunan yang pendek menghadap Utara dan Selatan, sehingga bidang terluas menghadap Timur dan Selatan dengan perletakan jendela yang juga menghadap Timur dan Selatan, dengan kondisi tersebut bagian dengan penampang terluas menerima radiasi matahari, yang lebih banyak yang mengakibatkan ruangan terasa makin panas.
Analisa Orientasi Bangunan Gedung Sekertariat Daerah terhadap angin

Terdapat bouvenlicht pada salah satu sisi dinding untuk menciptakan cross ventilation (ventilasi silang). Dengan model bouvenlicht seperti gambar di atas kurang ideal, dikarenakan masih minim untuk pertukaran udara masuk dan keluar (pergantian udara) yang menyebabkan ruang terasa panas karena kurang optimalnya sistem ventilasi silang. 


\section{Analisa Elemen Arsitektur (Pelindung Radiasi Matahari)}

Apabila posisi bangunan pada arah Timur dan Barat tidak dapat dihindari, maka pandangan bebas melalui jendela pada sisi ini harus dihindari karena radiasi panas yang langsung masuk ke dalam bangunan (melalui bukaan/kaca) akan memanaskan ruang dan menaikkan suhu/temperatur udara dalam ruang. Di samping itu efek silau yang muncul pada saat sudut matahari rendah juga sangat mengganggu. Karena pada gedung sekertariat daerah menggunakan desain jendela yang lebar dan menggunakan bahan kaca bening transparan tanpa dilengkapi elemen arsitektur seperti pelindung terhadap radiasi matahari (solar shading devices), ditambah jendela yang selalu tertutup korden maka cahaya matahari yang masuk tidak dapat tereduksi (terasa panas). Hal tersebut yang menyebabkan jendela selalu tertutup serta dilapisi dengan kain korden serta lebih memilih menggunakan penghawaan buatan dengan pendingin udara atau AC.

\section{SIMPULAN DAN SARAN}

Dari hasil analisis dan pembahasan dalam penelitian yang mengambil lokasi penelitian di Kantor Sekretariat Daerah Kabupaten Kudus dapat diambil simpulan sebagai berikut:

1) Dari hasil survei di tiga sampel ruang serta pengolahan data menunjukkan bahwa tingkat kenyamanan untuk :

a. Ruang Tamu - Lobby termasuk dalam kategori kondisi lingkungan yang sukar dengan suhu efektif $34.5^{\circ} \mathrm{C}$.

b. Ruang Badan Kepegawaian Daerah termasuk dalam kategori kondisi lingkungan yang tidak dapat ditolerir dengan suhu efektif $35.5^{\circ} \mathrm{C}$.

c. Ruang Kantor Kesatuan Bangsa dan Perlindungan Masyarakat (KESBANGLINMAS) termasuk dalam kategori kondisi lingkungan yang tidak dapat di tolerir dengan suhu efektif $35.5^{\circ} \mathrm{C}$.
2) Tidak adanya cross ventilation membuat keadaan tubuh terasa gerah karena pergantian udara tidak lancar.

3) Tidak adanya solar shading devices atau pelindung radiasi sinar matahari menjadikan ruangan menjadi lebih panas.

4) Dengan keadaan termal yang tidak ideal khususnya pada penghawaan hal itu menyebabkan dalam ruangan lebih menggunakan penghawaan buatan yang secara otomatis akan mempe-ngaruhi biaya operasional bangunan.

Dari hasil kesimpulan, analisa dan pembahasan dalam penelitian yang diambil dari Kantor Sekretariat Daerah Kabupaten Kudus dapat disarankan sebagai berikut:

1) Menciptakan kondisi termal sangat perlu diupayakan pada bangunan kantor untuk meningkatkan kiner-ja/aktifitas yang lebih optimal.

2) Perlunya studi/penelitian lanjutan dengan sampel ruang dan waktu pengukuran yang lebih panjang disertai analisa pergerakan udara eksternal.

3) Pemerintah daerah dalam hal ini Pemerintah Kabupaten Kudus harus berperan aktif dalam mengupayakan renovasi atau perbaikan infrastruktur dan sarana prasarana yang tidak layak agar kinerja staf pemerintahan bisa lebih optimal.

4) Kondisi ideal yang harus dibuat untuk menciptakan bangunan nyaman secara termal adalah sebagai berikut:

a. Teritis atap/Overhang harus dibuat cukup lebar.

b. Selubung bangunan (atap dan dinding) berwarna muda (meman-tulkan cahaya).

c. Mengupayakan terjadinya ventilasi silang.

d. Bidang-bidang atap dan dinding mendapat bayangan yang baik melalui vegetasi

e. Penyinaran langsung dari matahari dihalangi (menggunakan solar shading devices) untuk menghalangi panas dan silau. 


\section{DAFTAR PUSTAKA}

Boutet, Terry S. ,1987, Controlling Air Movement, New York: McGraw-Hill Book Company.

Departemen Pekerjaan Umum ,1993, Standar Tata Cara Perencanaan Teknis Konservasi Energi Pada Bangunan Gedung, Bandung: Yayasan LPMB.

Egan, M. David, 1975, Concept in Thermal Comfort, London: Prentice-Hall International.

Houghton dan Yaglou, 1923, dalam 'Determining Lines of Equal Comfort', Transactions of America Society of Heating and Ventilating Engineers Vol. 29

Lippsmeier, Georg ,1994, Building in the Tropics (terj.),Jakarta: Erlangga.

Mangunwijaya, Y.B., 1988, Pengantar Fisika Bangunan, Jakarta: Djambatan

Szokolay S.V, et. al ,1973, Manual of Tropical Housing and Building, Bombay: Orient Langman.

http://www.kudus.go.id/, Peta Wilayah Kota Kudus, diakses pada tanggal 20 Oktober 2011 